for Neurogenetics, RIKEN Brain Research Institute, Hirosawa 2-1, Wako-shi, Saitama 3510198, Japan).

CPMMENT. The syndrome of severe myoclonic epilepsy in infancy is characterized by normal development initially, onset of seizures during the first year, beginning with generalized or unilateral febrile clonic seizures, and followed by the secondary appearance of myoclonic seizures and partial seizures that are intractable and complicated by ataxia and mental deterioration. Genetic predisposition suggested by family history and concordant disease in monozygotic twins appears to be based on frameshift and nonsense mutations in the SCN1A gene.

\title{
HISTORY OF WEST SYNDROME
}

Historical details about Dr West, his son, James Edward West, the patient with infantile spasms, and the coining of the eponym 'West syndrome' are researched by pediatric neurologists and colleagues at the University of Nijmegen, the Netherlands; and University of California at Irvine. WJ West, a general practitioner at Tonbridge, UK, wrote a letter to the Lancet in 1841 (1:724725), entitled 'On a peculiar form of infantile convulsions.' To paraphrase, the infant was well until 4 months of age, when he began slight bobbings of the head forward, later a complete heaving of the head forward toward his knees, and then immediately relaxing into the upright position, similar to attacks of emprosthotonus. The patient was born Feb 13, 1840 and died at 20 years of age on Sept 27, 1860, having spent the last 7 years of his life in an Asylum for the FeebleMinded in Redhill, UK. He is buried with his father in the cemetery of the St Peter and Paul parochial church in Tonbridge. When Dr West's treatments failed (leeches, calomel, phlogiston, hot baths, alterantia drugs, opium), he consulted Drs Clarke and Locock in London, who called the seizures by the term 'Salaam convulsions,' having seen two similar cases previously. Subsequent early publications include those of Newnham (1849), using the term 'eclampsia nutans,' Fere (1883) who described 'tic de Salaam or salutation, and Zellweger (1948), who, like Fere, distinguished between symptomatic and idiopathic infantile spasms. Gibbs and Gibbs (1952) introduced the term 'hypsarrhythmia' and described the classical triad of diagnostic criteria, 'spasms, hypsarrhythmia, and mental retardation.' The term West syndrome was first suggested by Gastaut (1960) at the 9th Colloque de Marseille on infantile spasms, then called 'infantile myoclonic encephalopathy with hypsarrhythmia' (IMEH). (Eling P, Renier WO, Pomper J, Baram TZ. The mystery of the Doctor's son, or the riddle of West syndrome. Neurology March (2 of 2);58:953-955). (Reprints: Dr Paul Eling, NICI, PO Box 9104, 6500 HE Nijmegen, the Netherlands).

COMMENT. The advances made in the riddle of West syndrome, since it was first described 160 year ago, are the descriptive electroencephalographic abnormalities (hypsarrhythmia) by the Gibbs' (1952) and the introduction of ACTH (1958) by Sorel and Dusaucy-Bauloye, a largely empiric therapy. A study of etiologic factors in 61 patients with infantile West syndrome was published in 1962 (Millichap, Bickford, Klass, Backus, in Epilepsia 3:188), but the pathophysiology of the syndrome still eludes us (Baram, 1993). Incidentally, Tonbridge, the town in UK where West and his son are buried, is situated about 14 $\mathrm{km}$ north of Tunbridge Wells, the site of the Spastics Society and editorial office of the journal 'Dev Med Child Neurol.' 


\section{Prognosis of West syndrome}

A most current article on West syndrome out of Istanbul University, Turkey, concerns 'The informative value of magnetic resonance imaging and EEG in the prognosis of infantile spasms.' (Saltik S, Kocer, N, Dervent A. Epilepsia March 2002;43:246-252). A total of 86 cases, 8 cryptogenic and 78 symptomatic, were followed clinically and by video-EEG and MRI for $>1$ year. A significant correlation was determined between clinical and EEG findings, especially with regard to psychosocial development, and less so for motor development. MRI findings were correlated only with motor development. EEG and MRI are complementary in regard to prognostic informative value.

\section{TOPIRAMATE-INDUCED VALPROATE TOXICITY}

Three children with severe refractory epilepsy who developed typical valproate (VPA) adverse effects after introducing topiramate (TPM) in combination are reported from the University of Mannheim, Germany. Patient 1 was admitted at 16 months with psychomotor retardation and myoclonic seizures, subsequently diagnosed as Lennox-Gastaut syndrome. Initial treatment with carbamazepine (CBZ) and VPA was ineffective and the combination was changed to VPA and TPM. Apathy, loss of appetite, and fever developed after 4 weeks, and liver enzymes and ammonia levels were elevated. Recovery followed within 6 days after withdrawing VPA and TPM. All three patients developed severe typical VPA side effects with liver dysfunction during treatment with VPA and TPM, having tolerated VPA well in different AED combinations previously. VPA serum levels were within the normal range. One child had severe thrombocytopenia, and two had hypothermia, in addition to liver toxicity. All side effects were completely reversible after withdrawing VPA. (Longin E, Teich M, Koelfen W, Konig S. Topiramate enhances the risk of valproate-associated side effects in children. Epilepsia March 2002:43:451-454). (Reprints: Dr E Longin, University Children's Hospital, Theodor-Kutzer-Ufer, 68167 Mannheim, Germany).

COMMENT. The authors cite a report of 2 adult patients with severe typical VPA side effects that developed after treatment with VPA and TPM (Hamer et al. 2000). Symptoms of encephalopathy and hyperammonemia resolved after treatment was withdrawn. TPM appears to increase the risk of VPA toxicity when the drugs are used in combination. Careful monitoring of liver function and $\mathrm{CBC}$ is important when using VPA with TPM.

\section{TESTS OF ATTENTION IN NEWLY DIAGNOSED IDIOPATHIC EPILEPSY}

Performance on tests of Reaction Time, Color Trails, Manual Tapping and Steadiness, and Sustained Attention were compared in 51 children with epilepsy (age 7-16 years) and 48 healthy classmates, in a study at Wilhelmina Children's Hospital, Utrecht, the Netherlands. Execution times and motor speed were not significantly different in children with epilepsy and controls. Significantly more patients than controls had transient poor performance in one or other task $(69 \%$ cf $40 \%$ ). Patients with prior school or behavior difficulties and those whose parents could not adjust to a diagnosis of epilepsy performed worse than those without these additional problems. Epilepsy-related variables did not explain any variance in performance of attention and other tasks. (Oostrom KJ, Schouten A, Kruitwagen CLJJ et al. Attention deficits are not characteristic of schoolchildren with newly diagnosed idiopathic or cryptogenic epilepsy. Epilepsia March 2002;43:301-310). (Reprints: Dr KJ Oostrom, Department of Child Neurology, Division of 